\title{
ASPECTOS DA NATUREZA DA CIÊNCIA NAS PESQUISAS SOBRE CONTROVÉRSIAS SOCIOCIENTÍFICAS
}

\author{
ASPECTS OF THE NATURE OF SCIENCE IN RESEARCH ON \\ SOCIOSCIENTIFIC ISSUES
}

Carla Krupczak ${ }^{1}$

Joanez Aparecida Aires ${ }^{2}$

\begin{abstract}
Resumo: A literatura aponta que as controvérsias sociocientíficas (CSC) podem ser utilizadas para facilitar a compreensão da natureza da ciência (NDC). Com base nesta premissa, o objetivo desta investigação é analisar se a NDC é contemplada e, quando presente, quais aspectos desta são mais abordados nas pesquisas que versam sobre as CSC. Para tal, realizou-se uma pesquisa qualitativa do tipo estado do conhecimento. Os dados foram constituídos no Catálogo de Teses e Dissertações da CAPES e interpretados por meio da Análise Textual Discursiva. Os resultados indicaram que a NDC é pouco contemplada em trabalhos sobre CSC. Entretanto, mesmo quando a NDC não faz parte do objetivo central das atividades envolvendo CSC, aspectos da ciência aparecem nas discussões, dentre eles, o mais comum é a influência de fatores externos na ciência. Tendo em vista estes resultados, argumentamos que o potencial das CSC para a compreensão da NDC precisa ser mais explorado.
\end{abstract}

Palavras-chave: Questões Sociocientíficas; Epistemologia da Ciência; Educação Científica.

\begin{abstract}
The literature indicates that socioscientific issues (SSI) can facilitate the understanding of the nature of science (NOS). Based on that, the objective of this investigation is to analyze whether NOS is contemplated and, when present, which aspects of it are most addressed in the research that deals with SSI. For this end, a qualitative research of the state of knowledge type was carried out. The data was constituted in the CAPES Theses and Dissertations Catalog and interpreted through the Discursive Textual Analysis. The results indicated that the NOS is little considered in works on SSI. However, even when NOS is not part of the central objective of activities involving SSI, aspects of science appear in the discussions, among them, the most common is the influence of external factors in science. In view of these results, we argue that the potential of SSI for understanding NOS needs to be further explored.
\end{abstract}

Keywords: Socioscientific Issues; Epistemology of Science; Science Education.

\section{Introdução}

Um dos objetivos primordiais da educação científica é a formação de cidadãos alfabetizados cientificamente (HURD, 1998). Nesse sentido, pesquisadores da área de

\footnotetext{
${ }^{1}$ Mestra em Educação em Ciências e em Matemática, Universidade Federal do Paraná (UFPR). Doutoranda do Programa de Pós-Graduação em Educação em Ciências e em Matemática da Universidade Federal do Paraná (UFPR), Curitiba, Paraná, Brasil. E-mail: carlak.quim@gmail.com.

${ }^{2}$ Doutora em Educação Científica e Tecnológica, Universidade Federal de Santa Catarina (UFSC). Professora da Universidade Federal do Paraná (UFPR), Curitiba, Paraná, Brasil. E-mail: joanez.ufpr@gmail.com.
} 
DOI: https://doi.org/10.33238/ReBECEM.2020.v.4.n.4.26261

Ensino de Ciências defendem que a compreensão adequada da natureza da ciência (NDC) é um fator fundamental para a alfabetização científica (FARIA et. al., 2014; FERNANDES; RODRIGUES; FERREIRA, 2018; MENDONÇA, 2020). Em poucas palavras, entender a NDC significa saber o que é a ciência, como ela funciona e como afeta a vida das pessoas. Todavia, como alcançar esta compreensão sobre a NDC? Existem estratégias que pode propiciar a inclusão de reflexões sobre NDC? Sobre estas questões, já é possível encontrar na literatura algumas estratégias para aborda-las nas aulas. Uma perspectiva que vem sendo defendida mais recentemente corresponde às discussões sobre CSC (KARISAN; ZEIDLER, 2017; LEDERMAN; ANTINK; BARTOS, 2014), as quais são questões de cunho científico e tecnológico que envolvem aspectos políticos, econômicos, ambientais, morais e éticos, sociais, entre outros. As CSC são cada vez mais comuns, visto a grande dependência que as sociedades atuais têm da ciência e tecnologia. Assim, é fundamental que os cidadãos saibam compreendê-las, para que possam tomar decisões fundamentadas e cientes das consequências destas (HODSON, 2018).

As CSC envolvem, normalmente, conhecimento científico de fronteira, quer dizer, que ainda não está totalmente estabelecido, que está sendo discutido (REIS, 2004). Por isso, elas permitem a percepção de como ocorre o processo de construção da ciência, como os cientistas trabalham, que tipos de experimentos realizam, o que consideram evidências, como fatores externos afetam as pesquisas, quem financia as investigações e com quais objetivos, como a sociedade reage e é influenciada pela ciência, entre outros. Portanto, podem ser usadas para a compreensão da NDC. Por conta disto, o objetivo desta investigação é analisar se a NDC é contemplada e, quando presente, quais aspectos desta são mais abordados nas pesquisas que versam sobre as CSC. Para tanto, este artigo está estruturado primeiramente com uma breve revisão da literatura sobre NDC e CSC. Em seguida, a constituição e análise dos dados, finalizando com nossos achados no estudo.

\section{Um pouco sobre a natureza da ciência e as controvérsias sociocientíficas}

A natureza da ciência (NDC) vem sendo discutida, na educação científica, desde a segunda metade do século XIX (MATTHEWS, 2012). Durante todo este tempo muitas discussões e mudanças ocorreram, pois as concepções de NDC acompanham as pesquisas da filosofia, história e sociologia da ciência. Assim, houve períodos em que a NDC era 
DOI: https://doi.org/10.33238/ReBECEM.2020.v.4.n.4.26261

mais empirista, voltada para os aspectos internos da ciência, e outros momentos em que influências externas passaram a ser consideradas importantes (ABD-EL-KHALICK; LEDERMAN, 2000). No entanto,

[...] deve-se perceber que as concepções de NDC atualmente adotadas por educadores e organizações de educação em ciências não são 'inerentemente melhores' do que, por exemplo, as enfatizadas na década de 1960. É apenas com a vantagem de uma retrospectiva que tais comparações normativas podem ser feitas. Cada um dos conjuntos [...] de concepções de NDC, deve ser visto dentro do contexto do pensamento sistemático sobre conhecimento e prática científica que predominou no período em que esse conjunto foi adotado (ABDEL-KHALICK; LEDERMAN, 2000, p. 668, tradução nossa).

Ainda hoje existe muita discussão e "[...] torna-se bastante claro que não existe uma natureza singularmente preferida ou informada da ciência e que a natureza da ciência é tão experimental quanto, se não mais, do que o próprio conhecimento científico" (LEDERMAN, 1992, p. 352, tradução nossa). Neste artigo consideramos que:

\begin{abstract}
A natureza da ciência é uma arena híbrida fértil, que combina aspectos de vários estudos sociais da ciência, incluindo a história, a sociologia e a filosofia da ciência, combinados com pesquisas das ciências cognitivas, como a psicologia, em uma descrição rica do que é a ciência, como ela funciona, como os cientistas operam como um grupo social e como a própria sociedade se dirige e reage aos esforços científicos (MCCOMAS; CLOUGH; ALMAZROA, 1998, p. 4, tradução nossa).
\end{abstract}

Assim como existem diversas definições para a NDC, também existem várias justificativas para explicar porque ela deve estar presente na educação. Atualmente, um dos argumentos mais defendidos é que a compreensão da NDC é importante para o desenvolvimento da alfabetização científica dos estudantes (FARIA et al., 2014; FERNANDES; RODRIGUES; FERREIRA, 2018; MENDONÇA, 2020). Defende-se que cidadãos que compreendem a NDC conseguem entender melhor problemáticas científicas e tomar decisões mais críticas e fundamentadas. Por conta disso, mais de um terço das pesquisas brasileiras relacionadas com a NDC vem se concentrando em desenvolver estratégias didáticas que permitam incluir tal assunto nas aulas (KRUPCZAK; AIRES, 2018).

As discussões sobre a NDC feitas por filósofos, historiadores e sociólogos da ciência são bastante profundas e marcadas por diferenças. Assim, existe uma dificuldade em definir o que destas discussões deve ser levado para o ensino de ciências da educação básica. Pensando nisso, surgiu a chamada "visão consensual", a qual busca estabelecer alguns aspectos da NDC que são considerados consensos entre os especialistas e que 
podem, portanto, estar presentes nos currículos escolares. A lista de aspectos consensuais é variada, mas Pérez et al. (2001) resumem em cinco pontos principais:

1) Não existe um método científico. Os cientistas seguem sim metodologias padronizadas, mas estas são variadas, não consistem em um único conjunto de passos usado por todos os especialistas de todas as áreas;

2) Não existem dados puros e a observação não é neutra. Os dados constituídos pelos cientistas só fazem sentido quando são interpretados com base nas teorias existentes. Toda observação está embutida de conhecimentos prévios e expectativas;

3) O conhecimento científico não é uma verdade absoluta. Teorias, leis e modelos não são certezas, mas tentativas de resposta, as quais podem alterar-se. As observações são usadas para justificar hipóteses iniciais;

4) A busca pela coerência global. Os cientistas buscam criar teorias, leis e modelos o mais abrangentes possível, que acomodem o maior número de fenômenos e áreas;

5) A ciência possui um caráter social. Os cientistas não estão isolados do mundo, sendo influenciados pelo contexto sócio histórico que vivem. Além disso, os conhecimentos científicos afetam a forma como as pessoas vivem e interagem com o mundo.

McComas, Clough e Almazroa (1998) destacam que os aspectos consensuais são simplificações da NDC discutidas pelos especialistas. No entanto, para estudantes da educação básica, elas são suficientes para permitir a construção de concepções mais reais sobre a ciência. Existem outras propostas de como levar a NDC para a sala de aula, mas a visão consensual é a mais utilizada no Brasil, como apontam Alcantara e Braga (2017).

Independente de qual proposta seja utilizada o importante é que a NDC seja levada para a sala de aula. Pois, pesquisas apontam que os estudantes da educação básica e os cidadãos em geral, apresentam visões simplistas sobre a ciência, que não são condizentes com as epistemologias atuais (FERNANDES; RODRIGUES; FERREIRA, 2018). Outro dado ainda mais preocupante, é que os próprios professores e licenciandos possuem compreensões pouco adequadas de como funciona a ciência (PÉREZ et al., 2001; SCHEID; FERRARRI; DELIZOICOV, 2007; OKI; MORADILLO, 2008). A partir dos referidos dados, Pérez et al. (2001) elencaram sete principais visões deformadas sobre ciência, como foram chamadas pelos autores, as quais não são compatíveis com a visão consensual: 


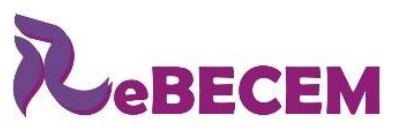

Revista Brasileira de Educação em

Ciências e Educação Matemática

DOI: https://doi.org/10.33238/ReBECEM.2020.v.4.n.4.26261

1) Visão empírico-indutivista e ateórica. Acredita que todo conhecimento é fruto de um experimento e que as observações são neutras, ou seja, não influenciadas pelos conhecimentos prévios dos cientistas. Novos conhecimentos são entendidos como descobertas;

2) Visão rígida. Destaca o método científico como única metodologia científica, sendo este um conjunto de passos a serem seguidos mecanicamente. Considera-se que o método científico garante confiabilidade aos resultados, por ter uma abordagem quantitativa e controle rigoroso;

3) Visão aproblemática e ahistórica. Ocorre quando apenas os produtos da ciência são apresentados, sem mencionar os problemas que deram origem aos conhecimentos e o contexto histórico em que foram construídos. Esta visão é transmitida por omissão, quer dizer, por falta de menção aos problemas originais;

4) Visão exclusivamente analítica. Destaca o caráter parcelar do conhecimento, as áreas científicas são entendidas como corpos de saber separados. Ignoram-se as teorias unificadoras e as tentativas de relacionar fenômenos;

5) Visão acumulativa de crescimento linear. Acredita que a ciência está sempre evoluindo em linha reta por pura acumulação de conhecimentos. As teorias atuais são vistas como melhores e mais completas que as anteriores. As crises, controvérsias e disputas entre teorias são desconsideradas;

6) Visão individualista e elitista. Entende que a ciência está reservada a uma elite intelectual especial. Os cientistas são considerados gênios, que trabalham sozinhos em seus laboratórios, sendo que a maioria são homens, brancos e europeus;

7) Visão socialmente neutra da ciência. Os cientistas são vistos como pessoas neutras, suas decisões não são influenciadas por fatores externos. As intrincadas relações entre a ciência, tecnologia e sociedade são esquecidas, a atividade científica está isolada do mundo, não sendo afetada pelo contexto social e histórico.

Pérez et al. (2001) destacam que estas visões não são isoladas, sendo comum que as pessoas apresentem mais de uma. A presença de tais concepções simplistas reforça a necessidade de incluir a NDC no ensino de ciências.

Segundo Abd-El-Khalick, Bell e Lederman (1998), existem duas maneiras de levar a NDC para as aulas: uma abordagem implícita e outra explícita. O primeiro tipo ocorre quando o docente não faz menções diretas à NDC, ele espera que o estudante aprenda as características da ciência apenas pelo contato com ela. Normalmente, esta abordagem envolve a realização de experimentos, enfatizando os procedimentos da 


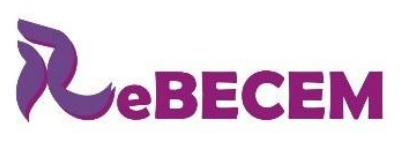

Revista Brasileira de Educação em

Ciências e Educação Matemática

DOI: https://doi.org/10.33238/ReBECEM.2020.v.4.n.4.26261

pesquisa científica. O segundo tipo ocorre quando o professor discute explicitamente os aspectos da NDC. Esta abordagem costuma envolver a discussão de casos da história da ciência.

A maior parte das pesquisas aponta que a abordagem explícita é a mais efetiva (ABD-EL-KHALICK; $\quad$ BELL; LERDERMAN， 1998; ABD-EL-KHALICK; LEDERMAN, 2000; FARIA et al., 2014; OKI; MORADILLO, 2008). Segundo Faria et al. (2014) a NDC deve ser entendida como um conteúdo, com a mesma importância que todos os outros, e, portanto, precisa de estratégias de ensino próprias. Desta forma, surgiram diversas propostas para a abordagem da NDC, sendo uma delas a discussão sobre controvérsias sociocientíficas (CSC).

Segundo Sadler e Zeidler (2004):

\begin{abstract}
As controvérsias sociocientíficas descrevem os dilemas da sociedade com vínculos conceituais, processuais ou tecnológicos à ciência. Muitas controvérsias sociocientíficas decorrem de dilemas envolvendo biotecnologia, problemas ambientais e genética humana. [...] os tópicos descritos pelo termo 'controvérsias sociocientíficas' exibem um grau único de interesse social, efeito e consequência. As controvérsias sociocientíficas são tipicamente contenciosas por natureza, podem ser consideradas a partir de uma variedade de perspectivas, não possuem conclusões simples e frequentemente envolvem moralidade e ética (SADLER; ZEIDLER, 2004, p. 5, tradução nossa).
\end{abstract}

Algumas características das CSC são: “[...] relacionar-se a ciência; envolver formação de opinião e escolhas; ter dimensão local, nacional ou global; envolver discussão de valores e ética; estar relacionado à vida; envolver discussão de benefícios, riscos e valores, entre outras." (MUNDIM; SANTOS, 2012, p. 791). Por tais particularidades, as CSC não podem ser resolvidas apenas com base em dados técnicos, o que as torna bastante diferente dos problemas que normalmente são resolvidas nas aulas de ciências. Além disso, as CSC envolvem, normalmente, conhecimento científico de fronteira, ainda não estabelecido por completo (REIS, 2004).

Alguns exemplos de CSC são: a produção e consumo de alimentos transgênicos, a eutanásia, o aborto, o aquecimento global, o uso de agrotóxicos na produção de alimentos, a clonagem de seres vivos, o uso de células-tronco, a construção de barragens de mineração em comunidades tradicionais, a energia nuclear, testes experimentais em animais, etc.

A discussão sobre CSC nas aulas de ciências vem sendo defendida pelas diversas habilidades que podem desenvolver nos estudantes, como as resumidas no Quadro 1 (KRUPCZAK, 2019). 
DOI: https://doi.org/10.33238/ReBECEM.2020.v.4.n.4.26261

\begin{tabular}{|c|l|}
\hline $\begin{array}{c}\text { Habilidades } \\
\text { sociais }\end{array}$ & $\begin{array}{l}\text { Comunicação, trabalho cooperativo, debater a fundamentação das opiniões, apoio entre } \\
\text { os indivíduos, saber escutar a opinião do outro, autoestima... }\end{array}$ \\
\hline \multirow{3}{\text{Habilidades}}{$\begin{array}{l}\text { Poder de argumentação, capacidade de analisar e explicar, pesquisa e recolha de } \\
\text { informações, detecção de incoerências em dados, avaliação da credibilidade das fontes, } \\
\text { pensar de forma crítica e formular opiniões próprias, reavaliar as próprias posições, } \\
\text { construção de hipóteses, independência intelectual, compreender as diversas dimensões } \\
\text { de uma situação... }\end{array}$} \\
\hline
\end{tabular}

Quadro 1: Habilidades que podem ser estimuladas na discussão sobre CSC.

Fonte: KRUPCZAK, 2019, p. 71.

Além disso, as CSC podem ser utilizadas como forma de abordar a NDC de maneira contextualizada e mais próxima da realidade dos estudantes. Segundo Zeidler e Nichols (2009, p. 53, tradução nossa) “[...] as unidades de estudo de CSC proporcionam o contexto para os alunos entenderem, através de experiências cuidadosamente elaboradas, que o conhecimento científico é carregado de teoria e social e culturalmente construído".

Hodson (2018) declara que as CSC explicitam os aspectos sociais internos e externos da ciência. $\mathrm{O}$ autor chama de caráter social interno da ciência, suas regras e valores, como racionalidade, objetividade, mente aberta, clareza, simplicidade, cautela, prudência, etc. Estas também podem ser utilizadas pelos indivíduos no processo de discussão e tomada de decisão relativamente às CSC. Por outro lado, o caráter social externo é o das relações ciência, tecnologia e sociedade, em que o contexto social e histórico influencia. Os estudantes precisam entender que tipo de ciência e tecnologia está presente nas CSC que estão analisando e como torná-las mais democráticas.

Reis (2004) afirma que quando os estudantes têm visões mais adequadas sobre a NDC, são mais capazes de avaliar informações, habilidade bastante pertinente, pois:

Habitualmente, a escola formal retrata a ciência como coerente, objetiva, não problemática e claramente distinguível de atividades não-científicas, veiculando um modelo de racionalidade científica que leva os alunos a pensarem que os métodos de investigação rigorosos revelam, de forma repetida, única e sem ambiguidades, fatos verdadeiros sobre o mundo natural. No entanto, a realidade é bem diferente. Os especialistas discordam frequentemente dos pareceres uns dos outros, razão pela qual se torna extremamente importante a capacidade de avaliar a qualidade das informações apresentadas pelas facções envolvidas. Por vezes, em algumas controvérsias (por exemplo, a coincineração de resíduos tóxicos), as questões técnicas não obtêm resposta apesar da vasta quantidade de informação técnica disponível e as facções acusam-se de enviesamento na seleção dos dados que fundamentam as respectivas opiniões (REIS, 2004, p. 49).

Portanto, pessoas que compreendem a NDC podem tomar melhores decisões relativamente às CSC. Quer dizer, existe uma via de mão dupla: 
DOI: https://doi.org/10.33238/ReBECEM.2020.v.4.n.4.26261

controvérsias sociocientíficas, mas também os contextos de CSC alteram a forma como os alunos respondem/entendem a NDC (KARISAN; ZEIDLER, 2017, p. 147, tradução nossa).

\section{Metodologia}

Esta é uma pesquisa qualitativa do tipo estado do conhecimento. Segundo Romanowski e Ens (2006), este tipo de investigação busca analisar a produção acadêmica sobre um tema com o objetivo de entender o que já foi estudado, os consensos estabelecidos, os pontos que ainda geram dúvidas e o que ainda não é conhecido. Para tal, podem ser utilizados artigos, atas de eventos, livros, teses e dissertações, entre outros, sendo este último tipo de material o usado nesta pesquisa.

Os dados foram constituídos a partir do Catálogo de Teses e Dissertações da CAPES. As expressões de pesquisa utilizadas foram: controvérsia(s) sociocientífica(s), questão(ões) sociocientífica(s), aspecto(s) sociocientífico(s), assunto(s) controverso(s) e tema $(s)$ controverso $(s)$. Estas expressões deveriam estar nos títulos, resumos ou palavraschave das teses e dissertações, sendo consideradas apenas as que foram defendidas em programas de pós-graduação das áreas de avaliação Ensino ou Educação, desde 1987, quando o catálogo começa, até 2017. Depois de retiradas as duplicatas, restaram 69 teses e dissertações defendidas nos últimos 30 anos. A distribuição das mesmas por ano e tipo pode ser observada na Figura $1^{3}$. As dissertações foram codificadas de D1 a D49 e as teses de T1 a T20. A lista com todas as teses e dissertações investigadas está no material complementar.

\footnotetext{
${ }^{3}$ A análise detalhada das tendências teóricas e metodológicas, estratégias didáticas e de formação de professores e lacunas envolvendo as pesquisas sobre CSC não é foco deste artigo. Mas, pode ser encontrada em Krupczak e Aires (2019).
} 
DOI: https://doi.org/10.33238/ReBECEM.2020.v.4.n.4.26261

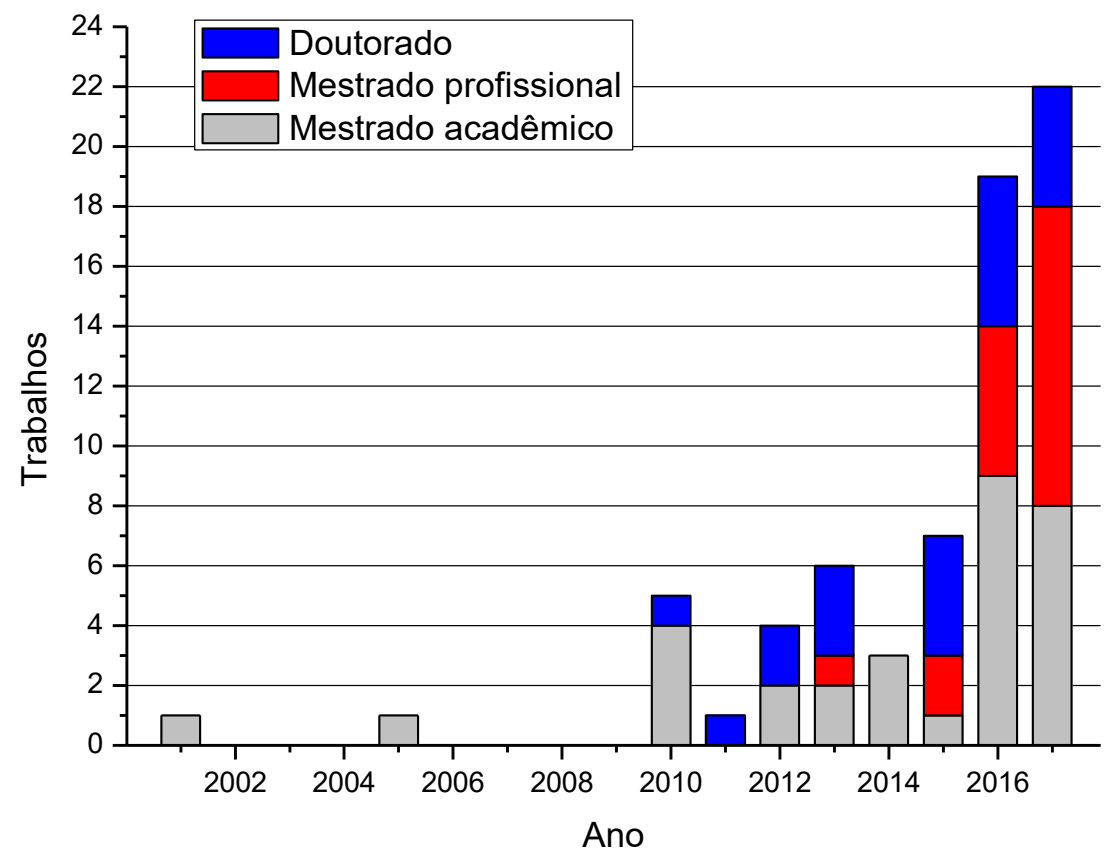

Figura 1: Distribuição das teses e dissertações conforme o ano e tipo.

Fonte: KRUPCZAK; AIRES (2019, p. 283).

A análise dos dados foi realizada por meio da Análise Textual Discursiva, que consiste em três etapas (MORAES; GALIAZZI, 2013). A primeira envolve a desmontagem dos textos, em que o pesquisador identifica as unidades de contexto (partes do texto) que são mais importantes para seu objetivo, buscando as unidades de significado (frases ou palavras) que representem o que se quer analisar. No caso desta investigação, as unidades de contexto corresponderam às partes dos textos que abordavam a ciência e, as unidades de significado, as frases que expressavam alguma característica da ciência. A segunda etapa é a do estabelecimento de relações, em que as unidades de significado são categorizadas. Nesta pesquisa, foram usadas 14 categorias a priori, que são as visões deformadas de Pérez et al. (2001) e as visões de enfrentamento de Silva e Aires (2014). As categorias serão melhor explicadas adiante. A última etapa é captando o novo emergente, que consiste na interpretação das categorias e a criação de relação entre elas. A validação dos resultados ocorre "[...] a partir da ancoragem dos argumentos na realidade empírica, o que é conseguido pelo uso de 'citações' de elementos extraídos dos textos do 'corpus'. A inserção crítica de excertos bem-selecionados dos textos originais constitui uma forma de validação" (MORAES; GALIAZZI, 2013, p. 39). Este processo de interpretação das categorias e demonstração por citações está nas próximas páginas deste artigo. 


\section{A natureza da ciência nas pesquisas sobre controvérsias sociocientíficas}

Todas as 69 teses e dissertações analisadas neste artigo versam sobre as CSC, no entanto, apenas quatro (D10, D23, T9 e T11) tinham objetivos gerais diretamente relacionados com a NDC. D10 analisou como ocorre a construção e funcionamento de um grupo de pesquisa com professores e como a compreensão da NDC poderia facilitar a discussão de CSC. D23 tinha como objetivo entender como a abordagem explícita da NDC no contexto das CSC pode afetar a imagem de ciência de alunos de Ensino Médio. T9 investigou como a população de Maringá percebe a ciência e a tecnologia presentes nos medicamentos. E T11 buscou conhecer as concepções sobre a NDC de licenciandos e entender como estas podem ser afetadas pela discussão de uma CSC.

Este número exíguo de quatro trabalhos, em um universo de 69, indica que, apesar da grande potencialidade das CSC para a discussão e compreensão da NDC, esta é uma abordagem ainda pouco conhecida pelos pesquisadores e professores brasileiros. No entanto, conforme já foi apontado, as CSC são situações que envolvem a ciência de fronteira, quer dizer, uma ciência que ainda está em processo de construção (REIS, 2004). Portanto, é muito difícil realizar a discussão de uma CSC sem mencionar, mesmo que rapidamente e implicitamente, algo sobre a NDC. Por isso, mesmo nas teses e dissertações em que o objetivo não era a compreensão da NDC, podem-se encontrar características desta, indícios de que ela poderia ter sido desenvolvida, caso fosse de interesse dos professores e pesquisadores envolvidos.

Tendo por base esta reflexão, buscamos identificar todos os trechos das 69 teses e dissertações que discutem algo que poderia remeter a alguma reflexão sobre a NDC, ou seja, sobre a construção, funcionamento e impactos da ciência na sociedade. Para a seleção desses trechos, foram utilizados os descritores do Quadro 2. As sete visões deformadas são as descritas por Pérez et al. (2001) e as setes visões de enfrentamento são apresentadas por Silva e Aires (2014).

\begin{tabular}{|l|l|}
\hline \multicolumn{1}{|c|}{ Visões deformadas (Pérez et al., 2001) } & \multicolumn{1}{c|}{ Visões de enfrentamento (Silva \& Aires, 2014) } \\
\hline $\begin{array}{l}\text { 1D. Socialmente neutra } \\
\text { Ignora-se o contexto histórico, social e político } \\
\text { da produção do conhecimento. }\end{array}$ & $\begin{array}{l}\text { 1E. Ciência influenciada por fatores externos } \\
\text { O contexto histórico, social e político influencia o que } \\
\text { e como é pesquisado. }\end{array}$ \\
\hline $\begin{array}{l}\text { 2D. Individualista e elitista } \\
\text { A ciência é feita por cientistas individuais, os } \\
\text { quais são gênios. }\end{array}$ & $\begin{array}{l}\text { 2E. Ciência como atividade coletiva } \\
\text { A ciência é realizada em grupos, com a troca de ideias. }\end{array}$ \\
\hline 3D. Empírico-indutivista e ateórica & 3E. Observação influenciada pela teoria \\
\hline
\end{tabular}


DOI: https://doi.org/10.33238/ReBECEM.2020.v.4.n.4.26261

\begin{tabular}{|l|l|}
\hline $\begin{array}{l}\text { A observação é neutra e apenas os } \\
\text { experimentos podem levar ao conhecimento }\end{array}$ & $\begin{array}{l}\text { Toda observação é feita com base em uma teoria } \\
\text { antecedente que guia o olhar do cientista. }\end{array}$ \\
\hline $\begin{array}{l}\text { 4D. Rígida } \\
\begin{array}{l}\text { Existe um método científico único, que é um } \\
\text { conjunto de etapas que todos os cientistas } \\
\text { seguem a risca. }\end{array}\end{array}$ & $\begin{array}{l}\text { 4E. Pluralismo metodológico } \\
\text { Não existe um método único, mas metodologias } \\
\text { variadas para cada tipo de pesquisa. }\end{array}$ \\
\hline $\begin{array}{l}\text { 5D. Aproblemática e ahistórica } \\
\text { Não são apresentados os problemas que deram } \\
\text { origem aos conhecimentos e estes são } \\
\text { considerados definitivos e verdadeiros. }\end{array}$ & $\begin{array}{l}\text { 5E. Caráter histórico e dinâmico da ciência } \\
\text { Mostra-se os problemas originais e a evolução do } \\
\text { leis e modelos. }\end{array}$ \\
\hline $\begin{array}{l}\text { 6D. Analítica } \\
\text { O conhecimento é dividido em partes, cada } \\
\text { área do conhecimento é considerada isolada. }\end{array}$ & $\begin{array}{l}\text { 6E. Unificação do conhecimento científico } \\
\text { Mostra-se a busca por integração e construção de } \\
\text { teorias abrangentes e coerentes. }\end{array}$ \\
\hline $\begin{array}{l}\text { 7D. Acumulativa de crescimento linear } \\
\text { Considera que o conhecimento científico está } \\
\text { sempre evoluindo e acumulando-se. }\end{array}$ & $\begin{array}{l}\text { 7E. Rupturas e controvérsias científicas } \\
\text { O conhecimento científico passa por questionamentos, } \\
\text { crises, mudanças, rupturas e controvérsias. }\end{array}$ \\
\hline
\end{tabular}

Quadro 2: Descritores da natureza da ciência.

Fonte: adaptado de Silva e Aires (2014).

\begin{tabular}{|c|l|c|}
\hline Descritor & \multicolumn{1}{|c|}{ Teses e dissertações } & Porcentagem \\
\hline $1 \mathrm{E}$ & D1, D3, D4, D5, D6, D7, D8, D9, D10, D11, D12, D13, D14, D15, D16, & $94,2 \%$ \\
& D17, D18, D19, D20, D21, D22, D23, D24, D25, D26, D27, D28, D29, & \\
& D30, D31, D32, D36, D37, D38, D39, D40, D41, D42, D43, D44, D45, & \\
& D46, D47, D48, D49, T1, T2, T3, T4, T5, T6, T7, T8, T9, T10, T11, & \\
& T12, T13, T14, T15, T16, T17, T18, T19, T20 & \\
\hline $5 \mathrm{E}$ & D1, D3, D5, D6, D7, D8, D9, D10, D11, D12, D13, D14, D15, D16, & $75,4 \%$ \\
& D17, D18, D19, D20, D21, D23, D25, D26, D27, D28, D29, D38, D39, & \\
& D41, D44, D45, D46, D48, D49, T1, T2, T3, T4, T5, T6, T7, T8, T9, & \\
\hline T10, T11, T12, T13, T14, T15, T16, T17, T18, T20 & $42,0 \%$ \\
\hline 3E & D1, D2, D3, D5, D6, D7, D13, D18, D20, D23, D25, D28, D31, D38, & \\
\hline & D41, D46, D47, T1, T3, T4, T5, T6, T8, T9, T10, T11, T12, T15, T16 & \\
\hline DE & T10, D11, D12, T13 & $27,5 \%$ \\
& D9, D10, D11, D13, D19, D26, D28, D29, D41, D45, T1, T6, T9, T10, & $26,1 \%$ \\
\hline T11, T12, T13, T17 & $21,7 \%$ \\
\hline DE & D9, D13, D14, D23, D28, D29, D44, T1, T3, T6, T8, T9, T10, T11, T12 & \\
\hline
\end{tabular}

Quadro 3: Descritores sobre a natureza da ciência encontrados na fundamentação teórica das teses e dissertações analisadas.

Fonte: as autoras (2020).

Os descritores do Quadro 2 foram usados para identificar os aspectos da NDC presentes, primeiramente, nos capítulos de fundamentação teórica das teses e dissertações. Os resultados quantitativos, relativos às análises realizadas, são apresentados no Quadro 3.

Os dados apontam, primeiramente, que nenhuma visão deformada foi encontrada na fundamentação teórica das teses e dissertações analisadas, ao contrário, foram encontradas apenas visões de enfrentamento. Isso mostra o amadurecimento da área de Educação em Ciências no quesito da NDC. Ou seja, os pesquisadores parecem já estar cientes das visões deformadas e não as propagam em seus trabalhos. 


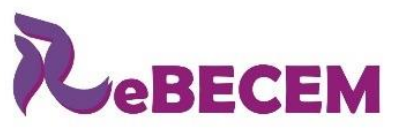

Revista Brasileira de Educação em

Ciências e Educação Matemática

DOI: https://doi.org/10.33238/ReBECEM.2020.v.4.n.4.26261

No que se refere às visões de enfrentamento, a mais presente nas pesquisas foi a 1E, ciência influenciada por fatores externos $(94,2 \%)$. Esta refere-se ao fato de que a ciência não é neutra, ela é afetada pelas questões sociais, políticas, econômicas, éticas e morais, ambientais e religiosas relativas ao momento histórico em que é construída. Até a década de 1960, a maioria dos epistemólogos e filósofos da ciência consideravam apenas os fatores internos à ciência como relevantes. Fleck (1981) foi um dos primeiros epistemólogos a considerar os fatores externos à ciência como importantes para a compreensão do desenvolvimento do conhecimento científico. Seu livro "Gênese e desenvolvimento de um fato científico" foi publicado em 1935, mas só recebeu destaque depois de 1979, quando foi traduzido para o inglês. Fleck (1981) estudou como se desenvolveu a compreensão sobre a sífilis, doença que era considerada "desonrosa", e mostrou que os aspectos sociais, como as crenças populares, afetaram o processo.

Em termos mais atuais, podemos notar a não neutralidade da ciência, e das pessoas que a fazem, em questões como o uso de agrotóxicos na agricultura. Existem diversas alternativas para a produção de alimentos com quantidades reduzidas ou mesmo zeradas de venenos, mas estas não são incentivadas. Isso ocorre por causa da grande influência que as corporações multinacionais que produzem tais agrotóxicos têm no meio político e econômico. Inclusive, esta é uma CSC recorrente nos meios de comunicação e de frequente disputa entre grupos de políticos, ambientalistas, população civil, agricultores, entre outros.

Portanto, não é surpreendente que a ciência influenciada por fatores externos seja o descritor mais recorrente nas teses e dissertações sobre CSC. Afinal, é muito difícil discutir as controvérsias atuais sem mencionar questões sociais, econômicas, políticas, éticas e morais, ambientais, entre outros. Um exemplo de trecho em que se pode notar tal aspecto da NDC é: “[...] é importante ressaltar a ciência como um processo social, na qual a comunidade científica está embebida em disputas, confrontos políticos e econômicos, como também, éticos e morais" (T5, p. 52, grifo nosso).

A segunda visão de enfrentamento mais frequente foi a $5 \mathrm{E}$, o caráter histórico $e$ dinâmico da ciência $(75,4 \%)$. Esta visão considera que o conhecimento científico não é estático, ele se transforma com o passar do tempo e isso pode ser notado nas CSC. Podemos ver, por exemplo, que na história do câncer já existiram diversas explicações para a doença e tratamentos dos mais variados tipos. As mudanças ocorrem por causa de novos estudos e aprofundamentos, com base em resultados e observações anteriores, bem 
como dos avanços tecnológicos e teóricos, que permitem a constituição de novos dados e a criação de novas explicações.

Pode-se notar um exemplo do descritor 5E no trecho:

\begin{abstract}
A partir de um enfoque histórico é possível caracterizar a Ciência como uma atividade humana e, mostrar que as interpretações sobre o fenômeno eletricidade foram se modificando ao longo da história e outras foram se somando para constituírem interpretações mais complexas e poderosas. Podemos, por exemplo, iniciar o trabalho educativo com o tema eletricidade abordando alguns aspectos que façam o aluno refletir sobre o status do conhecimento científico. Esta possibilidade, no entanto, exige partir do enfoque de que teorias e generalizações são conjeturais, de que ideias científicas podem mudar com o tempo, de que a Ciência lida com sistemas simplificados e idealizados e, por fim, de que a Ciência não é a única tentativa de explicar o mundo, mas o faz mediante um modelo racional poderoso (D1, p. 40, grifo nosso).
\end{abstract}

A terceira visão de enfrentamento mais recorrente é a 7E, rupturas e controvérsias científicas $(42,0 \%)^{4}$. Era esperado que este aspecto estivesse presente em todas as pesquisas que envolvem CSC. Afinal, elas são a melhor forma de evidenciar que a ciência não é constituída de verdades absolutas, mas que está repleta de controvérsias e disputas. Por exemplo, o consumo de alimentos transgênicos ainda é bastante contestável. Não existe consenso sobre os perigos ou não da ingestão deste tipo de alimento.

Pode-se perceber o descritor 7E no trecho "[...] a argumentação contribui com o desenvolvimento de uma imagem do trabalho científico, assim como de aspectos relacionados à natureza da ciência, como reconhecer que o conhecimento é mutável" (D17, p. 31, grifo nosso).

A quarta visão de enfrentamento mais recorrente foi a 3E, observação influenciada pela teoria (27,5\%). Aquilo que os cientistas veem ou não, depende dos seus referenciais teóricos, ou seja, da forma como entendem o mundo, das teorias em que se apoiam para estudar seus objetos. Assim, quando uma pessoa sem formação em medicina olha para um exame de laboratório, em que marcadores podem indicar um câncer, por exemplo, esta pessoa não entenderá o que aqueles valores significam. Já um médico irá identificar um tumor ou qualquer outro problema presente no exame. Isso ocorre porque o médico tem o olhar "treinado", orientado pela teoria, portanto sabe o que procura.

Exemplo deste aspecto da ciência pode ser visto no trecho: “[...] argumentação contribui com o desenvolvimento de uma imagem do trabalho científico, assim como de

\footnotetext{
${ }^{4}$ Controvérsias científicas são disputas entre diferentes grupos de cientistas, cada qual defendendo uma hipótese, teoria ou modelo. Portanto, são controvérsias internas à ciência e importantes para o desenvolvimento do conhecimento científico (REIS, 2009).
} 
DOI: https://doi.org/10.33238/ReBECEM.2020.v.4.n.4.26261

aspectos relacionados à natureza da ciência, como reconhecer que o conhecimento é mutável e que dados e provas são interpretados segundo as lentes teóricas do cientista" (D17, p. 31, grifo nosso).

A quinta visão de enfrentamento que mais aparece nas teses e dissertações é a 4E, pluralismo metodológico (26,1\%). Esses trabalhos confirmam o que é consenso entre epistemólogos influentes do século XX e XXI, que não existe um método científico único. Podemos encontrar tal descritor nas teses e dissertações, em trechos como:

Muitos filósofos da ciência, [...], são contrários à visão que alguns têm de que a Ciência é baseada no método empírico: observação, experimentação, leis, teorias e postulados. [...] na realidade, não há um só caminho na Ciência, mas sim várias possibilidades e que a Ciência não parte unicamente da observação, mas sim da teoria (D11, p. 21, grifo nosso).

Todavia, há que se esclarecer que a ciência não funciona de maneira aleatória, as metodologias existem, mas variam muito, principalmente, entre as diferentes áreas científicas. No entanto, existem algumas regras que costumam ser seguidas, como usar experimentos controlados, criar modelos e teorias que possam ser testados, aceitar apenas teorias que sejam consistentes, entre outras (IRZIK; NOLA, 2011).

A sexta visão de enfrentamento mais recorrente nas teses e dissertações foi a $2 \mathrm{E}$, ciência como atividade coletiva (21,7\%). A união e cooperação entre grupos de cientistas são cada vez mais frequentes, inclusive entre pesquisadores de áreas variadas. Por exemplo, na questão da AIDS, os cientistas das áreas biológicas e exatas buscam entender como a doença atinge o corpo, quais medicamentos podem ser usados, entre outros. Enquanto, no mesmo grupo de pesquisa, podem existir cientistas sociais tentando compreender como as interações entre as pessoas ocasionam a transmissão e como se pode prevenir e controlar a AIDS (HURD, 1998). O mesmo exemplo se aplica para a questão da COVID-19 atualmente, e tantos outros milhares de casos. Portanto, as controvérsias atuais podem ser usadas para evidenciar o caráter coletivo da ciência.

Exemplo deste descritor pode ser encontrado no trecho: "os conhecimentos científicos aparecem como obras de gênios isolados, ignorando-se o papel do trabalho coletivo e cooperativo, dos intercâmbios entre equipes" (D23, p. 6, grifo nosso).

$\mathrm{O}$ descritor menos abordado nas teses e dissertações foi o $6 \mathrm{E}$, unificação do conhecimento científico $(13,0 \%)$. Os cientistas buscam desenvolver teorias que tenham a maior abrangência possível, que expliquem o maior número de fenômenos e que interliguem áreas diferentes. Por exemplo, a teoria eletromagnética unificou o magnetismo com a eletricidade (PÉREZ et al., 2001). 


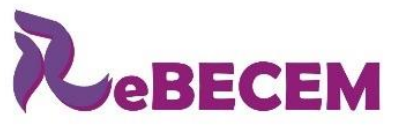

Revista Brasileira de Educação em

Ciências e Educação Matemática

DOI: https://doi.org/10.33238/ReBECEM.2020.v.4.n.4.26261

Podemos perceber esta visão de enfrentamento no trecho: "pelo contrário, aqueles trabalhos ou práticas que não fossem coerentes com o que estava estabelecido pelo coletivo científico eram rejeitados e considerados como conhecimento não científíco" (T11, p. 33, grifo nosso).

A maioria das teses e dissertações analisou, em algum momento da pesquisa, falas ou escritas de professores e estudantes (por meio de entrevistas, gravações de aulas e de discussões, trabalhos escritos, textos, entre outros). Assim, estes trechos foram analisados, de modo a identificar a presença dos descritores do Quadro 2 na forma de ver a ciência dos professores e alunos. Os resultados quantitativos são apresentados no Quadro 4.

\begin{tabular}{|c|l|c|}
\hline Descritor & \multicolumn{1}{|c|}{ Teses e dissertações } & Porcentagem \\
\hline 1E & D7, D12, D23, D28, D29, D41, T1, T6, T8, T11, T13 & $15,9 \%$ \\
\hline 5E & D7, D10, D12, D23, D28, D29, D41, T5, T11 & $13,0 \%$ \\
\hline 5D & D6, D10, D13, D25, T5, T8, T9, T11 & $11,6 \%$ \\
\hline 4D & D10, D13, D23, D28, T5, T11 & $8,7 \%$ \\
\hline 1D & D6, D10, D13, D23, T5, T11 & $8,7 \%$ \\
\hline 3D & D23, T5, T9, T11 & $5,8 \%$ \\
\hline 7D & D13, D28, T11 & $4,3 \%$ \\
\hline 2D & D23, T5, T11 & $4,3 \%$ \\
\hline 2E & D28, D29, T7 & $4,3 \%$ \\
\hline 6E & D10, D28, T11 & $4,3 \%$ \\
\hline 7E & D7, D29 & $2,9 \%$ \\
\hline 4E & D23, D29 & $2,9 \%$ \\
\hline 3E & T8 & $1,4 \%$ \\
\hline
\end{tabular}

Quadro 4: Descritores sobre a natureza da ciência encontrados nas falas ou escritas de professores e alunos das teses e dissertações analisadas.

Fonte: as autoras (2020).

Diferentemente dos resultados das visões de ciência na fundamentação teórica das pesquisas, em que todas foram de enfrentamento, nas falas e escritas dos professores e alunos, encontramos ambas as visões, sendo sete de enfrentamento e seis deformadas. No entanto, um aspecto bastante positivo diz respeito, especialmente às duas primeiras categorias (1E e 5E), as quais são de enfrentamento e se apresentaram em maior número. Consideramos que esta relação entre os dados está diretamente relacionada ao fato de que as atividades desenvolvidas pelos pesquisadores, para discutir e melhorar as compreensões sobre a NDC, foram eficientes em permitir a reflexão sobre os modos de ver a ciência por parte dos professores e alunos. Mas, também é possível encontrar menções às visões deformadas de ciência (nas quais a discussão focará agora). Tal fato não é surpreendente, visto a vasta literatura que indica que docentes e estudantes apresentam, comumente, compreensões pouco elaboradas sobre a NDC (FERNANDES; 
RODRIGUES; FERREIRA, 2018; OKI; MORADILLO, 2008; PÉREZ et al., 2001; SCHEID; FERRARRI; DELIZOICOV, 2007).

Entre as visões deformadas, a mais comum foi a 5D, aproblemática e ahistórica $(11,6 \%)$. Esta é uma visão que se transmite por omissão, ou seja, quando se apresentam apenas os produtos da ciência, sem mencionar o processo de construção. Assim, imaginase que a ciência está sempre evoluindo sem dificuldades e produzindo tecnologias cada vez melhores e mais avançadas, as quais sempre melhoram a vida das pessoas. Podemos notar tal descritor na seguinte frase de um licenciando: "a ciência é considerada atualmente como uma atividade que promove o progresso e o desenvolvimento técnico e tecnológico" (T11, p. 126, grifo nosso). Esta citação passa a impressão de que os produtos da ciência são sempre melhores e mais úteis.

A segunda visão deformada mais frequente foi a $4 \mathrm{D}$, rígida $(8,7 \%)$. É a compreensão de que existe um método científico único, que é seguido por todos os cientistas e que leva ao conhecimento verdadeiro. Esta visão pode ser percebida no texto escrito por uma licencianda: "[a ciência] possui metodologia estruturada para desenvolver processos investigativos. É verificável, ou seja, seus resultados podem ser verificáveis novamente. Procura fornecer uma resposta verificável aos fenômenos do mundo com base em um processo ou método" (T11, p. 108, grifo nosso).

A visão deformada $1 \mathrm{D}$, socialmente neutra $(8,7 \%)$, é a terceira mais comum nas falas e escritas de docentes e alunos. É a ideia de que a ciência, os cientistas e seus produtos são neutros, ou seja, não são afetados pelo meio social e estão sempre buscando melhorar a vida das pessoas. A visão socialmente neutra pode ser percebida na seguinte fala de uma licencianda: "as ciências buscam um fim, digamos, porque uma pessoa teve a ideia de desenvolver algo, por exemplo, a cura para o câncer, um cientista está preocupado em curar o câncer, então eu tenho que ver os aspectos químicos, biológicos, reações, mas qual é o fim? Ajudar uma população" (T11, p. 114). A fala revela a visão de que os cientistas estão sempre buscando melhorar a vida, independentemente de influências externas. No entanto, a realidade é que as pesquisas são desenvolvidas com interesses. Muitas vezes os cientistas optam por pesquisar assuntos que irão trazer mais prestígio para eles ou que terão maiores investimentos, ao invés daquilo que poderia ajudar um número maior de pessoas. Por exemplo, o câncer é uma doença bastante investigada, pois, existe um interesse econômico, já que é uma enfermidade que demora meses para ser tratada e cujo tratamento é caro. Por outro lado, existem doenças que são negligenciadas pela indústria farmacêutica, como malária, esquistossomose ou doença de 
DOI: https://doi.org/10.33238/ReBECEM.2020.v.4.n.4.26261

Chagas, as quais recebem menos investimento para pesquisa, pois são enfermidades que atingem, majoritariamente, as populações mais pobres dos países menos desenvolvidos.

A quarta visão deformada que mais aparece é a 3D, empírico-indutivista $e$ ateórica $(5,8 \%)$. É a ideia de que a experimentação é a parte mais importante do trabalho dos cientistas e que as observações realizadas são neutras, sem teorias que as fundamentem. Um exemplo de frase que revela esta visão é: "[a ciência] é objetiva no estudo dos fenômenos do mundo, deve primar a imparcialidade para evitar erros na sua implementação" (T11, p. 109, grifo nosso).

O quinto descritor de visão deformada mais recorrente nas falas e escritas de docentes e alunos é o 7D, acumulativa de crescimento linear (4,3\%). Esta visão considera que a ciência está sempre evoluindo de forma linear, com os conhecimentos acumulandose. As teorias atuais são consideradas melhores e mais completas que as anteriores. Percebe-se esta visão no seguinte trecho de conversa:

Licenciando: [a ciência] sempre evolui, falamos sobre isso porque não está estática, o mundo está mudando, então, como dizíamos a tecnologia tem que avançar porque já existem ramos como a Biologia, sobre o assunto das doenças.

Professora: um exemplo básico é que antes se pensava que a Terra era o centro, a teoria geocentrista.

Outro licenciando: [...], por exemplo, a matemática na época grega, era diferente, não havia sistema de medição, houve a necessidade de criar um sistema de medição (T11, p. 121, grifo nosso).

O último descritor encontrado nas falas e escritas de docentes e alunos foi o $2 \mathrm{D}$, individualista e elitista (4,3\%). É a visão deformada que considera que os cientistas trabalham sozinhos. Além disso, eles são vistos de forma estereotipada, são gênios, normalmente homens, loucos, sem vida social, que estão sempre trancados no laboratório, entre outros. Pode-se notar tal descritor no seguinte trecho, escrito por uma licencianda:

A ciência é individualista, uma vez que cada um dos chamados cientistas
procura solucionar algumas dúvidas sobre o ser humano, mas isso, por sua vez,
não compartilha com o ser a quem ele quer ajudar, já que ele se tranca em um
laboratório e realiza experimentos que antes do contato com um ser humano
o faz com um animal, o qual sofrerá as consequências das decisões tomadas
por esse cientista, caso haja falhas, a vida do 'porquinho-da-índia', como esses
cientistas chamam, é como um objeto, para quem quer descobrir e inovar nos
problemas da ciência não vale absolutamente nada, por não ser humano, de
pensamentos e sentimentos, esses mesmos cientistas declararam esses seres
vivos animais irracionais e sem nenhum tipo de afeto (T11, p. 111 , grifo
nosso).

O descritor 6D, a visão deformada analítica, não foi encontrado em falas e escritas de docentes e alunos. 

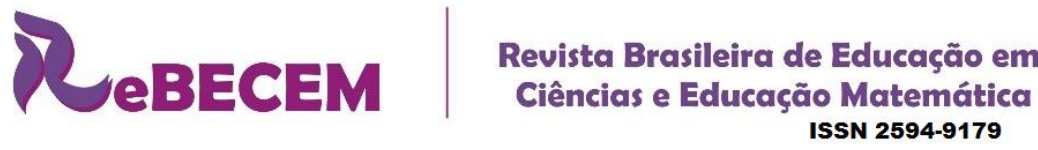

DOI: https://doi.org/10.33238/ReBECEM.2020.v.4.n.4.26261

A análise realizada neste artigo indica que a NDC sempre pode ser abordada na discussão sobre CSC e acaba aparecendo mesmo quando não é um objetivo explícito. Nos casos em que os professores e estudantes demonstraram possuir visões deformadas de ciência, os pesquisadores poderiam ter aproveitado o momento de discussão da CSC para incitar reflexões sobre a NDC. No entanto, o pequeno número de trabalhos que busca relacionar as duas temáticas indica que a maioria dos pesquisadores desconhece o potencial das CSC para a compreensão da NDC e acaba "perdendo a oportunidade".

\section{Conclusões}

O objetivo desta pesquisa foi analisar se a NDC é contemplada e, quando presente, quais aspectos desta são mais abordados nas pesquisas que versam sobre as CSC. Os resultados mostraram que são pouquíssimos os trabalhos que aproveitam as potencialidades das CSC para abordar a NDC, apenas quatro trabalhos tinham objetivos gerais diretamente relacionados com a NDC. Mas, mesmo quando esta não é um objetivo explícito e direto, é inevitável não abordar algumas características da ciência. A análise mostrou que os pesquisadores da área de Educação em Ciências já superaram as visões deformadas e não as transmitem mais em seus textos. No entanto, elas ainda estão presentes entre professores e alunos, o que é corroborado pela literatura da área.

Dentre os descritores de enfrentamento utilizados neste artigo, o mais presente foi o 1E, ciência influenciada por fatores externos. Tal dado era esperado, visto o caráter complexo das CSC. Seria quase impossível discutir tais questões sem mencionar como os aspectos sociais, morais e éticos, políticos, ambientais, econômicos, entre outras, afetam a ciência e as situações relacionadas a ela. As relações entre a ciência, a tecnologia e a sociedade ficam latentes e tornam-se fundamentais para a tomada de decisão.

Os resultados desta investigação vão ao encontro da pesquisa de revisão realizada por Karisan e Zeidler (2017) que mostra que, no âmbito internacional, também são poucos os pesquisadores que utilizam as CSC como forma de abordar a NDC. No entanto, os trabalhos que existem indicam as potencialidades de tal abordagem. Como as CSC estão envoltas, muitas vezes, em conhecimento científico que ainda não está totalmente estabelecido, elas permitem a visualização do funcionamento da ciência. Portanto, fornecem uma oportunidade única para a compreensão de diversos aspectos da NDC de forma atual e contextualizada. 


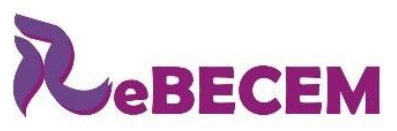

Revista Brasileira de Educação em

Ciências e Educação Matemática

DOI: https://doi.org/10.33238/ReBECEM.2020.v.4.n.4.26261

O mundo está se tornando progressivamente mais dependente da ciência e tecnologia e as CSC são cada vez mais comuns. Por isso, uma educação científica que promova a alfabetização científica precisa envolver a compreensão da NDC e a discussão sobre CSC. No entanto, esta pesquisa mostra que estas questões ainda são pouco abordadas em conjunto (apenas quatro trabalho tiveram como objetivos relacionar a NDC e as CSC), existindo muitas lacunas teóricas e práticas que precisam ser estudadas. Por exemplo, são raríssimas as propostas didáticas e exemplos de atividades que usam as CSC para abordar a NDC. Por isso, espera-se que este artigo estimule a produção de novas pesquisas, as quais possam subsidiar o trabalho dos professores de ciências.

\section{Referências}

ABD-EL-KHALICK, F.; BELL, R. L.; LERDERMAN, N. G. The nature of science and instructional practice: making the unnatural natural. Science Education, Tallahassee, v. 82, n. 4, p. 417-436, 1998.

ABD-EL-KHALICK, F.; LEDERMAN, N. G. Improving science teachers' conceptions of nature of science: A critical review of the literature. International Journal of Science Education, London, v. 22, n. 7, p. 665-701, 2000.

ALCANTARA, M. C.; BRAGA, M. Natureza da Ciência: um estudo das influências teóricas em trabalhos publicados em periódicos brasileiros. Enseñanza de las Ciencias, Barcelona, n. Extra, p. 3643-3648, 2017.

FARIA, C.; FREIRE, S.; GALVÃO, C.; REIS, P.; FIGUEIREDO, O. "Como trabalham os cientistas?": potencialidades de uma atividade de escrita para a discussão acerca da natureza da ciência nas aulas de ciências. Ciência \& Educação, Bauru, v. 20, n. 1, p. 1-22, 2014.

FERNANDES, G. W.; RODRIGUES, A. M.; FERREIRA, C. A. R. Elaboração e validação de um instrumento de análise sobre o papel do cientista e a natureza da ciência e da tecnologia. Investigações em Ensino de Ciências, Porto Alegre, v. 23, n. 2, p. 256-290, 2018.

FLECK, L. Genesis and development of a scientific fact. 1. ed. Chicago; London: University of Chicago Press, 1981.

HODSON, D. Realçando o papel da ética e da política na educação científica: algumas considerações teóricas e práticas sobre questões sociocientíficas. In: CONRADO, D. M.; 
DOI: https://doi.org/10.33238/ReBECEM.2020.v.4.n.4.26261

NUNES-NETO, N. (Orgs.). Questões sociocientíficas: fundamentos, propostas de ensino e perspectivas para ações sociopolíticas. 1. ed. Salvador: EDUFBA, 2018, p. 27-57.

HURD, P. D. Scientific literacy: New minds for a changing world. Science Education, Tallahassee, v. 82, n. 3, p. 407-416, 1998.

IRZIK, G.; NOLA, R. A family resemblance approach to the nature of science for science education. Science \& Education, Dordrecht, v. 20, n. 7-8, p. 591-607, 2011.

KARISAN, D.; ZEIDLER, D. L. Contextualization of nature of science within the socioscientific issues framework: A review of research. International Journal of Education in Mathematics, Science and Technology, Ancara, v. 5, n. 2, p. 139-152, 2017.

KRUPCZAK, C. Natureza da ciência nas pesquisas sobre controvérsias sociocientíficas: o estado do conhecimento no contexto brasileiro. 2019. 171 f. Dissertação (Mestrado em Educação em Ciências e em Matemática) - Setor de Ciências Exatas, Universidade Federal do Paraná, Curitiba, 2019.

KRUPCZAK, C.; AIRES, J. A. Natureza da ciência: o que os pesquisadores brasileiros discutem?. Amazônia: Revista de Educação em Ciências e Matemáticas, Manaus, v. 14, n. 32, p. 19-32, 2018.

KRUPCZAK, C.; AIRES, J. A. Controvérsias sociocientíficas: uma análise da produção acadêmica brasileira. Vidya, Santa Maria, v. 39, n. 1, p. 277-290, 2019.

LEDERMAN, N. G. Students' and teachers' conceptions of the nature of science: A review of the research. Journal of Research in Science Teaching, Chapel Hill, v. 29, n. 4, p. 331-359, 1992.

LEDERMAN, N. G.; ANTINK, A.; BARTOS, S. Nature of science, scientific inquiry, and socio-scientific issues arising from genetics: A pathway to developing a scientifically literate citizenry. Science \& Education, Dordrecht, v. 23, n. 2, p. 285-302, 2014.

MATTHEWS, M. R. Changing the focus: from nature of science to features of science. In: KHINE, M. S. (Ed.). Advances in Nature of Science Research. 1. ed. Dordrecht: Springer, 2012. p. 3-26.

MCCOMAS, W. F.; CLOUGH, M. P.; ALMAZROA, H. The role and character of the nature of science in science education. In: MCCOMAS, W. F. (Ed.). The Nature of Science in Science Education: rationales and strategies. 1. ed. New York: Kluwer Academic Publishers, 1998, p. $3-40$.

MENDONÇA, P. C. C. De que Conhecimento sobre Natureza da Ciência Estamos Falando?. Ciência \& Educação, Bauru, v. 26, p. 1-16, 2020. 
MORAES, R.; GALIAZZI, M. C. Análise Textual Discursiva. 2. ed. Ijuí: Unijuí, 2013.

MUNDIM, J. V.; SANTOS, W. L. P. D. Ensino de ciências no ensino fundamental por meio de temas sociocientíficos: análise de uma prática pedagógica com vista à superação do ensino disciplinar. Ciência \& Educação, Bauru, v. 18, n. 4, p. 787-802, 2012.

OKI, M. D. C. M.; MORADILLO, E. F. D. O ensino de história da química: contribuindo para a compreensão da natureza da ciência. Ciência \& Educação, Bauru, v. 14, n. 1, p. 67-88, 2008.

PÉREZ, D. G.; MONTORO, I. F.; ALÍS, J. C.; CACHAPUZ, A.; PRAIA, J. Para uma imagem não deformada do trabalho científico. Ciência \& Educação, Bauru, v. 7, n. 2, p. 125-153, 2001.

REIS, P. Controvérsias sócio-científicas: discutir ou não discutir?: percursos de aprendizagem na disciplina de ciências da Terra e da vida. 2004. 488 f. Tese (Doutorado em Educação) - Departamento de Educação, Universidade de Lisboa, Lisboa, 2004.

ROMANOWSKI, J. P.; ENS, R. T. As pesquisas denominadas do tipo" estado da arte" em educação. Revista Diálogo Educacional, Curitiba, v. 6, n. 19, p. 37-50, 2006.

SADLER, T. D.; ZEIDLER, D. L. The morality of socioscientific issues: Construal and resolution of genetic engineering dilemmas. Science Education, Tallahassee, v. 88, n. 1, p. 427, 2004.

SCHEID, N. M. J.; FERRARI, N.; DELIZOICOV, D. Concepções sobre a natureza da ciência num curso de ciências biológicas: imagens que dificultam a educação científica. Investigações em Ensino de Ciências, Porto Alegre, v. 12, n. 2, p. 157-181, 2007.

SILVA, E. C. C.; AIRES, J. A. Análise das visões sobre a natureza da ciência em produções científicas que se reportam a livros didáticos. Filosofia e História da Biologia, São Paulo, v. 9, n. 2, p. 141-160, 2014.

ZEIDLER, D. L.; NICHOLS, B. H. Socioscientific issues: Theory and practice. Journal of Elementary Science Education, Berna, v. 21, n. 2, p. 49-58, 2009.

Recebido em: 09 de novembro de 2020

Aceito em: 08 de dezembro de 2020 
Quadro 1: Teses e dissertações brasileiras sobre controvérsias sociocientíficas defendidas entre 1987 e 2017.

\begin{tabular}{|c|c|}
\hline Código & Referência \\
\hline D1 & $\begin{array}{l}\text { SILVA, L. F. A temática ambiental e o ensino de física na escola média: a produção de } \\
\text { energia elétrica em larga escala como um tema controverso. } 172 \mathrm{f} \text {. Dissertação (Mestrado } \\
\text { em Educação Escolar) - Universidade Est. Paulista Júlio de Mesquita Filho, São Paulo, } 2001 .\end{array}$ \\
\hline D2 & $\begin{array}{l}\text { HERNÁNDEZ, V. A. N. Educação ambiental e temas controversos: os conflitos } \\
\text { socioambientais no contexto de um processo de formação continuada. } 160 \text { f. Dissertação } \\
\text { (Mestrado em Educação) - Universidade Est. Paulista Júlio de Mesquita Filho/Rio Claro, } \\
\text { Rio Claro, 2005. }\end{array}$ \\
\hline D3 & $\begin{array}{l}\text { CARMO, B. C. R. Padrões morais, valores e conceitos empregados por alunos de ensino } \\
\text { fundamental em discussões sociocientíficas. } 190 \text { f. Dissertação (Mestrado em Ensino de } \\
\text { Ciências - Modalidades Física, Química e Biologia) - Universidade De São Paulo, São Paulo, } \\
2010 \text {. }\end{array}$ \\
\hline D4 & $\begin{array}{l}\text { ASEM, E. C. A. D. Argumentos, conhecimentos e valores em respostas a questões } \\
\text { sociocientíficas - um caso no ensino fundamental. } 140 \text { f. Dissertação (Mestrado em Ensino } \\
\text { de Ciências - Modalidades Física, Química e Biologia) - Universidade de São Paulo, São } \\
\text { Paulo, } 2010 \text {. }\end{array}$ \\
\hline D5 & $\begin{array}{l}\text { BARBOSA, L. G. D. O debate sobre o aquecimento global em sala de aula: o sujeito } \\
\text { dialógico e a responsabilidade do ato frente a um problema sócio-científico controverso. } 80 \\
\text { f. Dissertação (Mestrado em Educação) -Universidade Federal de Minas Gerais, Belo } \\
\text { Horizonte, } 2010 \text {. }\end{array}$ \\
\hline D6 & $\begin{array}{l}\text { LOPES, N. C. Aspectos formativos da experiência com questões sociocientíficas no } \\
\text { ensino de ciências sob uma perspectiva crítica. } 230 \text { f. Dissertação (Mestrado em Educação } \\
\text { para a Ciência) - Universidade Est. Paulista Júlio de Mesquita Filho/Bauru, Bauru, } 2010 \text {. }\end{array}$ \\
\hline T1 & $\begin{array}{l}\text { PEREZ, L. F. M. A abordagem de questões sociocientíficas na formação continuada de } \\
\text { professores de ciências: contribuições e dificuldades. } 351 \mathrm{f} \text {. Tese (Doutorado em Educação } \\
\text { para a Ciência) - Universidade Est. Paulista Júlio de Mesquita Filho/Bauru, Bauru, 2010. }\end{array}$ \\
\hline $\mathrm{T} 2$ & $\begin{array}{l}\text { GUIMARÃES, M. A. Raciocínio informal e a discussão de questões sociocientíficas: o } \\
\text { exemplo das células-tronco humanas. } 222 \text { f. Tese (Doutorado em Educação para a Ciência) } \\
\text { - Universidade Est. Paulista Júlio de Mesquita Filho/Bauru, } 2011 \text {. }\end{array}$ \\
\hline D7 & $\begin{array}{l}\text { CARNIO, M. P. O Significado Atribuído por Licenciados ao Currículo de Biologia sob } \\
\text { uma Perspectiva CTSA. } 195 \text { f. Dissertação (Mestrado em Educação para a Ciência) - } \\
\text { Universidade Est. Paulista Júlio de Mesquita Filho/Bauru, Bauru, 2012. }\end{array}$ \\
\hline D8 & $\begin{array}{l}\text { PEREIRA, G. F. S. Apropriação de conhecimentos científicos: uma abordagem aos } \\
\text { alimentos transgênicos. } 119 \text { f. Dissertação (Mestrado em Educação em Ciências e } \\
\text { Matemática) - Universidade Federal do Pará, Belém, 2012. }\end{array}$ \\
\hline $\mathrm{T} 3$ & $\begin{array}{l}\text { PENHA, S. P. Atividades sociocientíficas em sala de aula de física: as argumentações dos } \\
\text { estudantes. } 485 \text { f. Tese (Doutorado em Ensino de Ciências - Modalidades Física, Química e } \\
\text { Biologia) - Universidade de São Paulo, São Paulo, } 2012 \text {. }\end{array}$ \\
\hline $\mathrm{T} 4$ & $\begin{array}{l}\text { MENDES, M. R. M. A argumentação em discussões sociocientíficas: o contexto e o } \\
\text { discurso. } 211 \text { f. Tese (Doutorado em Educação) - Universidade de Brasília, Brasília, } 2012 .\end{array}$ \\
\hline D9 & $\begin{array}{l}\text { SOUSA, G. P. Educação CTS e genética, elementos para a sala de aula: potencialidades } \\
\text { e desafios. } 317 \text { f. Dissertação (Mestrado em Educação Científica e Formação de Professores) } \\
\text { - Universidade Estadual do Sudoeste da Bahia, Jequié, } 2013 \text {. }\end{array}$ \\
\hline D10 & $\begin{array}{l}\text { SANTOS, P. G. F. O tratamento de questões sociocientíficas em um grupo de } \\
\text { professores e a natureza do processo formativo fundamentado em uma perspectiva } \\
\text { crítica. } 209 \text { f. Dissertação (Mestrado em Educação para a Ciência) - Universidade Est. } \\
\text { Paulista Júlio de Mesquita Filho/Bauru, Bauru, } 2013 \text {. }\end{array}$ \\
\hline D11 & $\begin{array}{l}\text { SILVA, A. K. M. Abordagem de temas CTS em uma escola particular: análise de uma } \\
\text { experiência vivenciada. } 158 \text { f. Dissertação (Mestrado Profissional em Ensino de Ciências) - } \\
\text { Universidade de Brasília, Brasília, 2013. }\end{array}$ \\
\hline $\mathrm{T} 5$ & $\begin{array}{l}\text { BORTOLETTO, A. Formação Continuada de Professores: A Experiência de uma } \\
\text { Temática Sociocientífica na Perspectiva do Agir Comunicativo. } 237 \text { f. Tese (Doutorado em } \\
\text { Educação para a Ciência) - Universidade Est. Paulista Júlio de Mesquita Filho/Bauru, Bauru, } \\
2013\end{array}$ \\
\hline
\end{tabular}


DOI: https://doi.org/10.33238/ReBECEM.2020.v.4.n.4.26261

\begin{tabular}{|c|c|}
\hline T6 & $\begin{array}{l}\text { TEIXEIRA, C. H. S. Enfoque CTSA no ensino de astronomia: uma investigação de } \\
\text { possibilidades por meio da astronáutica. } 203 \mathrm{f} \text {. Tese (Doutorado em Educação para a } \\
\text { Ciência) - Universidade Est. Paulista Júlio de Mesquita Filho/Bauru, Bauru, 2013. }\end{array}$ \\
\hline T7 & $\begin{array}{l}\text { LOPES, N. C. A constituição de associações livres e o trabalho com as questões } \\
\text { sociocientíficas na formação de professores. } 389 \mathrm{f} \text {. Tese (Doutorado em Educação para a } \\
\text { Ciência) - Universidade Est. Paulista Júlio de Mesquita Filho/Bauru, Bauru, } 2013 \text {. }\end{array}$ \\
\hline D12 & $\begin{array}{l}\text { SILVA, V. H. D. Limites e possibilidades na inserção de questões sociocientíficas: um } \\
\text { estudo com professores da educação básica. } 113 \text { f. Dissertação (Mestrado em EDUCAÇÃO) } \\
\text { - UNIVERSIDADE FEDERAL FLUMINENSE, Niterói, } 2014 .\end{array}$ \\
\hline D13 & $\begin{array}{l}\text { MARCELINO, L. V. Compreensões de professores sobre abordagens da biotecnologia } \\
\text { no ensino de química. } 283 \text { f. Dissertação (Mestrado em Educação Cientifica e Tecnológica) } \\
\text { - Universidade Federal de Santa Catarina, Florianópolis, } 2014 \text {. }\end{array}$ \\
\hline D14 & $\begin{array}{l}\text { TOLEDO, V. A. O. Ações didáticas de um professor de física sobre uma questão } \\
\text { sociocientífica. } 105 \text { f. Dissertação (Mestrado em Educação) - Universidade Federal } \\
\text { Fluminense, Niterói, } 2014 \text {. }\end{array}$ \\
\hline D15 & $\begin{array}{l}\text { LEITE, V. L. O estudo das diversas formas de produção de energia em uma abordagem } \\
\text { ctsa: buscando indícios de alfabetização científica de estudantes do ensino médio. } 112 \mathrm{f} \text {. } \\
\text { Dissertação (Mestrado Profissional em Ensino de Física) - Universidade Federal do Espírito } \\
\text { Santo, Vitória, } 2015 \text {. }\end{array}$ \\
\hline D16 & $\begin{array}{l}\text { STADLER, J. P. Análise de aspectos sociocientíficos em questões do Enem: subsídio para } \\
\text { a elaboração de material didático para a formação cidadã. } 115 \text { f. Dissertação (Mestrado } \\
\text { Profissional em Formação Científica, Educacional e Tecnológica) - Universidade } \\
\text { Tecnológica Federal do Paraná, Curitiba, 2015. }\end{array}$ \\
\hline D17 & $\begin{array}{l}\text { SOUSA, P. S. Argumentação centrada em questões sociocientíficas e educação } \\
\text { problematizadora: possibilidades para o ensino de ciências. } 148 \text { f. Dissertação (Mestrado } \\
\text { em Educação em Ciências) - Universidade Estadual de Santa Cruz, Ilhéus, } 2015\end{array}$ \\
\hline T8 & $\begin{array}{l}\text { BARBOSA, L. G. D. Circulação de sentidos e posicionamentos dos sujeitos na } \\
\text { abordagem do aquecimento global como tema controverso: um olhar Bakhtiniano. } 270 \\
\text { f. Tese (Doutorado em Educação) - Universidade Federal de Minas Gerais, Belo Horizonte, } \\
2015\end{array}$ \\
\hline T9 & $\begin{array}{l}\text { PEDRANCINI, V. D. Percepção pública da ciência e da tecnologia dos medicamentos: } \\
\text { subsídios para o ensino de ciências. } 317 \text { f. Tese (Doutorado em Educação para a Ciência) - } \\
\text { Universidade Est. Paulista Júlio de Mesquita Filho/Bauru, Bauru, } 2015 \text {. }\end{array}$ \\
\hline T10 & $\begin{array}{l}\text { DUSO, L. A discussão de controvérsias sociocientíficas: uma perspectiva integradora no } \\
\text { ensino de ciências. } 248 \text { f. Tese (Doutorado em Educação Cientifica e Tecnológica) - } \\
\text { Universidade Federal de Santa Catarina, Florianópolis, } 2015 \text {. }\end{array}$ \\
\hline T11 & $\begin{array}{l}\text { SIERRA, D. F. M. Compreensões sobre a natureza da ciência de licenciandos a partir } \\
\text { da experiência com questões sociocientíficas: possibilidades para a formação inicial. } 248 \\
\text { f. Tese (Doutorado em Educação para a Ciência) - Universidade Est. Paulista Júlio de } \\
\text { Mesquita Filho/Bauru, Bauru, 2015. }\end{array}$ \\
\hline D18 & $\begin{array}{l}\text { OLIVEIRA, T. C. Educação CTS: uma experiência didática com o tema substâncias } \\
\text { psicoativas. } 217 \text { f. Dissertação (Mestrado Profissional em Ensino de Ciências e Matemática) } \\
\text { - Instituto Federal de Educação, Ciência e Tecnologia de São Paulo, São Paulo, } 2016 .\end{array}$ \\
\hline D19 & $\begin{array}{l}\text { ANDRADE, M. A. S. Construção e Aplicação de uma Sequência Didática Colaborativa } \\
\text { a partir de uma Questão Sociocientífica sobre Agrotóxicos na Perspectiva CTSA. } 233 \\
\text { f. Dissertação (Mestrado em Ensino, Filosofia e História Das Ciências) - Universidade } \\
\text { Federal da Bahia, Salvador, } 2016 \text {. }\end{array}$ \\
\hline D20 & $\begin{array}{l}\text { SILVA, D. P. As dimensões ética e científica na formação para tomada de decisão sobre } \\
\text { uso de animais nas ciências em um contexto de educação cts. } 134 \mathrm{f} \text {. Dissertação } \\
\text { (Mestrado em Ensino, Filosofia e História das Ciências) - Universidade Federal da Bahia, } \\
\text { Salvador, } 2016 \text {. }\end{array}$ \\
\hline D21 & $\begin{array}{l}\text { COSTA, L. C. Biologia no ensino médio: os transgênicos em questão. } 95 \text { f. Dissertação } \\
\text { (Mestrado em Educação) - Centro Universitário Moura Lacerda, Ribeirão Preto, } 2016 .\end{array}$ \\
\hline D22 & $\begin{array}{l}\text { MELO, V. F. O júri simulado como recurso didático para promover argumentações na } \\
\text { formação inicial de professores de física. } 152 \text { f. Dissertação (Mestrado em Educação) - } \\
\text { Universidade Federal Fluminense, Niterói, } 2016 .\end{array}$ \\
\hline D23 & $\begin{array}{l}\text { MARTINS, M. R. Ensino Explicito e Integrado de Natureza da Ciência e Argumentação } \\
\text { em um Contexto Sociocientífico para Estudos de Química do Ensino Médio. } 174 \text { f. }\end{array}$ \\
\hline
\end{tabular}


DOI: https://doi.org/10.33238/ReBECEM.2020.v.4.n.4.26261

\begin{tabular}{|c|c|}
\hline & $\begin{array}{l}\text { Dissertação (Mestrado em Educação) - Universidade Federal de Minas Gerais, Belo } \\
\text { Horizonte, } 2016 .\end{array}$ \\
\hline D24 & $\begin{array}{l}\text { LENHARO, A. F. L. A potencialidade do uso de questões sociocientíficas para a } \\
\text { produção do gênero do discurso dissertação escolar. } 155 \mathrm{f} \text {. Dissertação (Mestrado } \\
\text { Profissional em Docência para a Educação Básica) - Universidade Estadual Paulista Júlio de } \\
\text { Mesquita Filho/Bauru, Bauru, } 2016 \text {. }\end{array}$ \\
\hline D25 & $\begin{array}{l}\text { RAMIREZ, N. K. G. Produção de significados por professores de ciências sobre } \\
\text { currículo centrado em questões sociocientíficas: contribuições para a formação do } \\
\text { professor pesquisador. } 117 \text { f. Dissertação (Mestrado em Educação nas Ciências) - Univ. } \\
\text { Regional do Noroeste do Estado do Rio Grande do Sul, Ijuí, 2016. }\end{array}$ \\
\hline D26 & $\begin{array}{l}\text { FIGUEIRA, M. J. S. Contribuição de Práticas Argumentativas Para a Democratização } \\
\text { de Debates Científicos em Aulas De Física. } 147 \text { f. Dissertação (Mestrado em Educação } \\
\text { para a Ciência) - Universidade Estadual Paulista Júlio de Mesquita Filho/Bauru, Bauru, } \\
2016 \text {. }\end{array}$ \\
\hline D27 & $\begin{array}{l}\text { CARNEIRO, G. A. A interação museu-escola sob o referencial teórico metodológico das } \\
\text { ilhas interdisciplinares de racionalidade. } 165 \text { f. Dissertação (Mestrado em Educação para } \\
\text { a Ciência) - Universidade Estadual Paulista Júlio de Mesquita Filho/Bauru, Bauru, } 2016 .\end{array}$ \\
\hline D28 & $\begin{array}{l}\text { SILVA, M. A. A. Ciência, tecnologia e sociedade, experimentação e formação inicial de } \\
\text { professores de química: explorando possibilidades. } 418 \text { f. Dissertação (Mestrado em } \\
\text { Educação Científica e Formação de Professores) - Universidade Estadual do Sudoeste da } \\
\text { Bahia, Jequié, } 2016 \text {. }\end{array}$ \\
\hline D29 & $\begin{array}{l}\text { MELLO, T. E. T. Diferentes abordagens no desenvolvimento de uma sequência de } \\
\text { ensino CTSA/QSC sobre aquecimento global por três professores em escolas públicas } \\
\text { de minas gerais. } 110 \text { f. Dissertação (Mestrado Profissional em Educação e Docência) - } \\
\text { Universidade Federal de Minas Gerais, Belo Horizonte, } 2016 \text {. }\end{array}$ \\
\hline D30 & $\begin{array}{l}\text { TEIXEIRA, A. M. Questões sociocientíficas na sala de aula de Ciências no ensino } \\
\text { fundamental na perspectiva do agir comunicativo. } 142 \text { f. Dissertação (Mestrado } \\
\text { Profissional em Formação Científica, Educacional e Tecnológica) - Universidade } \\
\text { Tecnológica Federal do Paraná, Curitiba, 2016. }\end{array}$ \\
\hline D31 & $\begin{array}{l}\text { DUTRA, L. C. M. Unidade, diversidade e continuidade celular: repensando o ensino de } \\
\text { células no ensino médio. } 136 \text { f. Dissertação (Mestrado Profissional em Ensino de Ciências) } \\
\text { - Fundação Universidade Federal de Mato Grosso do Sul, Campo Grande, } 2016 .\end{array}$ \\
\hline T12 & $\begin{array}{l}\text { SILVA, S. M. B. A moral em questões sociocientíficas no ensino de biologia. } 271 \text { f. Tese } \\
\text { (Doutorado em Educação) - Universidade de Brasília, Brasília, } 2017 .\end{array}$ \\
\hline T13 & $\begin{array}{l}\text { BARBOSA, L. C. A. A problematização do princípio da precaução na formação do } \\
\text { técnico agrícola: reflexões para o enfrentamento da racionalidade instrumental a partir de } \\
\text { uma questão sociocientífica. } 351 \mathrm{f} \text {. Tese (Doutorado em Educação Cientifica e Tecnológica) } \\
\text { - Universidade Federal de Santa Catarina, Florianópolis, 2016. }\end{array}$ \\
\hline T14 & $\begin{array}{l}\text { SOBRINHO, M. F. Temas sociocientíficos no Enem e no livro didático: limitações e } \\
\text { potencialidades para o ensino de Física. } 349 \text { f. Tese (Doutorado em Educação) - } \\
\text { Universidade de Brasília, Brasília, 2016. }\end{array}$ \\
\hline T15 & $\begin{array}{l}\text { RIBEIRO, K. D. F. Formação de professores de ciências naturais em uma perspectiva } \\
\text { interdisciplinar e crítica: reflexões sobre a contribuição da vivência com questões } \\
\text { sociocientíficas na mobilização e aprendizagem de conhecimentos para a docência. } 357 \mathrm{f} \text {. } \\
\text { Tese (Doutorado em Educação em Ciências e Matemática) - Universidade Federal de Mato } \\
\text { Grosso, Cuiabá, 2016. }\end{array}$ \\
\hline T16 & $\begin{array}{l}\text { SILVA, K. M. A. E. Questões sociocientíficas e o pensamento complexo: tessituras para } \\
\text { o ensino de ciências. } 303 \text { f. Tese (Doutorado em Educação) - Universidade de Brasília, } \\
\text { Brasília, 2016. }\end{array}$ \\
\hline D32 & $\begin{array}{l}\text { SILVA, V. H. S. Projeto 'Redepesca': debates sobre Atividades Pesqueiras na Educação } \\
\text { Profissional de Nível Médio. } 130 \text { f. Dissertação (Mestrado Profissional em Educação em } \\
\text { Ciências e Matemática) - Instituto Federal de Educação, Ciência e Tecnologia do Espírito } \\
\text { Santo, Vitória, 2017. }\end{array}$ \\
\hline D33 & $\begin{array}{l}\text { SILVA, R. M. Argumentação no ensino de ciências e temas controversos: possibilidades } \\
\text { para pensar a embriologia nas aulas da educação básica. } 97 \text { f. Dissertação (Mestrado } \\
\text { Profissional em Docência em Educação em Ciências e Matemática) - Universidade Federal } \\
\text { do Pará, Belém, } 2017 \text {. }\end{array}$ \\
\hline
\end{tabular}


DOI: https://doi.org/10.33238/ReBECEM.2020.v.4.n.4.26261

\begin{tabular}{|c|c|}
\hline D34 & $\begin{array}{l}\text { CALDERAN, A. P. Ensino e aprendizagem de química a partir da temática 'tintas para } \\
\text { tatuagem'. } 234 \text { f. Dissertação (Mestrado em Educação em Ciências) - Universidade Federal } \\
\text { De Santa Maria, Porto Alegre, } 2017 .\end{array}$ \\
\hline D35 & $\begin{array}{l}\text { ARAUJO, S. N. Produção de uma sequência didática com abordagem socioambiental } \\
\text { na educação de jovens e adultos. } 108 \text { f. Dissertação (Mestrado Profissional em Educação } \\
\text { e Docência) - Universidade Federal de Minas Gerais, Belo Horizonte, } 2017 .\end{array}$ \\
\hline D36 & $\begin{array}{l}\text { SANTOS, J. C. Ética ambiental no ensino de ciências a partir de questões } \\
\text { sociocientíficas para a educação básica. } 104 \mathrm{f} \text {. Dissertação (Mestrado em Ensino, Filosofia } \\
\text { e História das Ciências) - Universidade Federal da Bahia, Salvador, } 2017 .\end{array}$ \\
\hline D37 & $\begin{array}{l}\text { SILVA, D. K. A controvérsia agroecológica em uma abordagem intercultural de } \\
\text { educação científica: a biodiversidade nos discursos de licenciandos do campo. } 116 \mathrm{f} \text {. } \\
\text { Dissertação (Mestrado em Educação) - Universidade Federal do Triângulo Mineiro, } \\
\text { Uberaba, } 2017 \text {. }\end{array}$ \\
\hline D38 & $\begin{array}{l}\text { GONÇALVES, M. B. Concepções de licenciandos de ciências biológicas e professores } \\
\text { de ciências sobre mudanças climáticas: relacionando educação ambiental e educação em } \\
\text { ciências a partir da abordagem de controvérsias sociocientíficas. } 111 \text { f. Dissertação } \\
\text { (Mestrado em Educação em Ciências e Saúde) - Universidade Federal do Rio de Janeiro, } \\
\text { Rio de Janeiro, } 2017 \text {. }\end{array}$ \\
\hline D39 & $\begin{array}{l}\text { OLIVEIRA, J. R. Proposta de uma Sequência Didática fundamentada na Teoria Ator } \\
\text { Rede: O Estatuto do Embrião. } 126 \text { f. Dissertação (Mestrado Profissional em Ensino de } \\
\text { Ciências) - Universidade Federal de Ouro Preto, Ouro Preto, } 2017 .\end{array}$ \\
\hline $\mathrm{D} 40$ & $\begin{array}{l}\text { FADINI, G. P. Desenvolvimento de um projeto de educação alimentar com enfoque } \\
\text { CTS/CTSA no contexto do ensino médio público. } 110 \text { f. Dissertação (Mestrado } \\
\text { Profissional em Educação em Ciências e Matemática) - Instituto Federal de Educação, } \\
\text { Ciência e Tecnologia do Espírito Santo, Vitória, 2017. }\end{array}$ \\
\hline D41 & $\begin{array}{l}\text { VALE, W. K. M. Um olhar sobre os processos de apropriação e objetivação da } \\
\text { abordagem de questões sociocientíficas na formação de professores de ciências } \\
\text { naturais. } 155 \text { f. Dissertação (Mestrado em Ensino das Ciências) - Universidade Federal } \\
\text { Rural de Pernambuco, Recife, } 2017 \text {. }\end{array}$ \\
\hline $\mathrm{D} 42$ & $\begin{array}{l}\text { GOMES, L. C. A. Funções orgânicas e aulas temáticas: uma proposta de atividade em } \\
\text { uma feira livre. } 93 \text { f. Dissertação (Mestrado Profissional em Ensino de Ciências) - Instituto } \\
\text { Federal de Educação, Ciência e Tecnologia do Rio de Janeiro, Nilópolis, } 2017 .\end{array}$ \\
\hline D43 & $\begin{array}{l}\text { MANTOVANI, E. E. Práticas curriculares e questões sociocientíficas: possibilidades } \\
\text { para um ensino de ciências reflexivo. } 107 \text { f. Dissertação (Mestrado em Ensino e História das } \\
\text { Ciências e da Matemática) - Universidade Federal do ABC, Santo André, } 2017 .\end{array}$ \\
\hline D44 & $\begin{array}{l}\text { OLIVEIRA, D. A. A. S. Tessituras sociocientíficas no contexto da horta escolar: com o } \\
\text { protagonismo infantil das narrativas à produção literária. } 195 \text { f. Dissertação (Mestrado } \\
\text { Profissional em ENSINO DE CIÊNCIAS) - Instituto Federal de Educação, Ciência e } \\
\text { Tecnologia do Rio de Janeiro, Nilópolis, 2017. }\end{array}$ \\
\hline D45 & $\begin{array}{l}\text { GOMES, T. M. Formação continuada de professores por meio da investigação-ação: } \\
\text { resistência e autonomia docente na abordagem de questões sociocientíficas. } 107 \mathrm{f} \text {. } \\
\text { Dissertação (Mestrado Profissional em Formação Científica, Educacional e Tecnológica) - } \\
\text { Universidade Tecnológica Federal do Paraná, Curitiba, } 2017 \text {. }\end{array}$ \\
\hline D46 & $\begin{array}{l}\text { MOREIRA, C. S. Questões sociocientíficas e mediação pedagógica: contribuições para o } \\
\text { ensino de ciências. } 154 \text { f. Dissertação (Mestrado Profissional em Educação Científica e } \\
\text { Matemática) - Universidade Estadual de Mato Grosso do Sul, Dourados, } 2017 \text {. }\end{array}$ \\
\hline D47 & $\begin{array}{l}\text { SILVA, A. E. M. Implementação das questões sociocientíficas (qscs) no processo de } \\
\text { ensino e aprendizagem da física no ensino médio Manaus. } 124 \text { f. Dissertação (Mestrado } \\
\text { em Ensino de Ciências e Matemática) - Universidade Federal do Amazonas, Manaus, } 2017 .\end{array}$ \\
\hline D48 & $\begin{array}{l}\text { SANTANA, R. C. M. Projeto 'mascavo': educação química a partir dos estudos culturais } \\
\text { da construção social de ciência e tecnologia da produção artesanal de açúcar. } 156 \text { f. } \\
\text { Dissertação (Mestrado Profissional em Educação em Ciências e Matemática) - Instituto } \\
\text { Federal de Educação, Ciência e Tecnologia do Espírito Santo, Vitória, 2017. }\end{array}$ \\
\hline D49 & $\begin{array}{l}\text { PINHEIRO, A D. A inserção de questões sociocientíficas na prática docente dos } \\
\text { participantes do pibid biologia da UFABC. } 114 \mathrm{f} \text {. Dissertação (Mestrado em Ensino e } \\
\text { História das Ciências e da Matemática) - Universidade Federal do ABC, Santo André, } 2017 .\end{array}$ \\
\hline T17 & $\begin{array}{l}\text { SANTOS, P. G. F. As questões sociocientíficas na formação de professores: o pequeno } \\
\text { grupo de pesquisa como comunidade de experiência. } 216 \mathrm{f} \text {. Tese (Doutorado em Educação }\end{array}$ \\
\hline
\end{tabular}


DOI: https://doi.org/10.33238/ReBECEM.2020.v.4.n.4.26261

\begin{tabular}{|l|l|}
\hline & $\begin{array}{l}\text { para a Ciência) - Universidade Estadual Paulista Júlio de Mesquita Filho/Bauru, Bauru, } \\
\text { 2017. }\end{array}$ \\
\hline T18 & $\begin{array}{l}\text { CARNIO, M. P. A experiência formativa de professores no trabalho com uma questão } \\
\text { sociocientífica: potencialidades e obstáculos em um Pequeno Grupo de Pesquisa. } 314 \mathrm{f} . \\
\text { Tese (Doutorado em Educação para a Ciência) - Universidade Estadual Paulista Júlio de } \\
\text { Mesquita Filho/Bauru, Bauru, 2017. }\end{array}$ \\
\hline T19 & $\begin{array}{l}\text { GENOVESE, C. L. C. R. Elaboração do Trabalho de Conclusão de Curso na graduação } \\
\text { em Pedagogia sob a perspectiva da educação por meio das questões sociocientíficas: } \\
\text { uma análise a partir dos conceitos de formação e semiformação de Adorno. } 308 \text { f. Tese } \\
\text { (Doutorado em Educação para a Ciência) - Universidade Estadual Paulista Júlio de Mesquita } \\
\text { Filho/Bauru, Bauru, 2017. }\end{array}$ \\
\hline T20 & $\begin{array}{l}\text { CONRADO, D. M. Questões Sociocientíficas na Educação CTSA: contribuições de um } \\
\text { modelo teórico para o letramento científico crítico. 239 f. Teses (Doutorado em Ensino, } \\
\text { Filosofia e História das Ciências) - Universidade Federal da Bahia, Salvador, 2017. }\end{array}$ \\
\hline
\end{tabular}

